\title{
Caracterización dos cambios na superficie agrícola mediante técnicas de regresión: comarca de Terra Chá, 1956-2004
}

Recibido: 11 xaneiro 2010 / Aceptado: 30 setembro 2010

(C) IBADER- Universidade de Santiago de Compostela 2010

\begin{abstract}
Resumo Os cambios do uso do solo, especialmente aqueles que afectan dun modo ou outro á actividade agrícola, constitúen un tema de grande interese en Galicia debido ás importantes repercusións de tipo ambiental, económico e cultural que implican. Non obstante, estes atópanse en grande medida pendentes de ser estudados, particularmente desde o punto de vista territorial e a escala detallada. Neste traballo preséntase a utilización dunha técnica de base estatística para avaliar a influencia de diversas variables de tipo biofísico, estrutural e socioeconómico sobre a distribución xeográfica dos cambios que afectaron á superficie agrícola na comarca de Terra Chá entre os anos 1956 e 2004. Os resultados mostran que se ben o cese da actividade agrícola tivo lugar preferentemente nas áreas máis difíciles de mecanizar e máis afastadas das explotacións, con carácter xeral este deu lugar á rexeneración natural do mato nas áreas máis afastadas dos núcleos de poboación e situadas a maior altitude, mentres que deu lugar á existencia de arborado en moitas áreas máis accesibles. Respecto da transición en sentido contrario (de mato a superficie agrícola), evidénciase nos resultados a grande importancia de variables relativas ás características estruturais das parcelas na roturación de terras de monte para ser utilizadas pola agricultura na actualidade.
\end{abstract}

Palabras clave abandono da agricultura · cambios de usos do solo · sistemas de información xeográfica · regresión loxística · fotografía aérea

Eduardo Corbelle Rico · Inés Santé Riveira Grupo Inv. 1934-TeBio, Laboratorio do Territorio (LaboraTe) Dpto. Enxeñería Agroforestal, Escola Politécnica Superior Universidade de Santiago de Compostela

Campus Universitario s/n, 27002. Lugo. http://laborate.usc.es Tel. 982285900 - ext. 23292

E-mail: eduardo.corbelle@usc.es
Abstract Changes of land use, particularly those affecting agriculture, constitute an important issue in Galicia due to the consequences they carry from the environmental, economic and cultural points of view. Nevertheless, it is largely pending of being studied in greater detail, especially from the perspective of its location on the territory. This paper presents the use of statistical tools to evaluate the influence of several biophysical, structural, social and economic variables on the pattern of changes affecting the the distribution of agricultural land in the district of Terra Chá in the period 1956-2004. Among other results, it is shown that although the abandonment of agriculture took place mainly in less productive parcels located far from farms, the result of this transition was different in those areas located at higher altitude and farther from populated places (where shrubs covered most of former agricultural plots) and in more accessible areas where tree cover increased significantly. The opposite transition (from shrublands to agricultural use) was demonstrated to be closely correlated with the structure of parcels.

Key words agricultural abandonment - land use change . geographic information systems $\cdot$ logistic regression · aerial photography

\section{Introdución}

As transformacións sociais e tecnolóxicas que afectaron ó sector agrario galego durante a segunda metade do século $\mathrm{XX}$ tiveron como un dos principais resultados a diminución continua do número de explotacións e polo tanto da superficie dedicada á agricultura, e sentaron dese modo as bases dunha boa parte dos problemas ambientais e económicos que afectan ó sector agrario galego. Entre as contribucións recentes a esta área temática pódense citar as que se aproximan á evolución do sector agrario desde a entrada de España na CEE (López Iglesias, 2000), as que tratan de achegarse ó problema mediante a análise das estatísticas de uso do solo (Soto Fernández, 2006; Corbelle Rico \& Crecente Maseda, 2009), ou aquelas que estudan os factores que motivan o peche das explotacións individuais 
(Sineiro García et al., 2004). Con todo, apréciase no panorama bibliográfico sobre a materia a necesidade de traballos a unha escala máis fina que a proporcionada polas fontes estatísticas máis comúns, que permitan establecer algún tipo de patrón territorial seguido polos cambios que afectaron á superficie agrícola en Galicia.

O estudo deste patrón territorial é o obxecto dos estudios de cambio de uso do solo, denominación xenérica baixo a que se inclúe unha grande variedade de técnicas. Con frecuencia, as aproximacións utilizadas nos estudos de cambios de uso teñen un carácter puramente empírico, xa que se trata de atopar relacións (non necesariamente causais) entre os cambios observados na cuberta do solo e un conxunto de variables seleccionadas. Máis aínda, é frecuente que as variables utilizadas se seleccionen fundamentalmente con criterios de dispoñibilidade e que por esta razón non sexan estritamente relevantes para o proceso estudado senón, no mellor dos casos, variables proxy (variables que teñen escaso valor por si mesmas pero que presentan forte correlación con algunha outra, máis interesante desde o punto de vista teórico, que non está dispoñible). Trátase por tanto de modelos que xeran coñecemento indutivo (tratan de comprender o proceso a través das pautas observadas) e que por esta razón teñen unha utilidade máis descritiva que explicativa dos procesos estudados. Se ben en ocasións se ten indicado a natureza máis interesante, desde o punto de vista da solidez das conclusións, dos métodos de tipo dedutivo (Walker \& Solecki, 2004; Overmars et al., 2007), os modelos de tipo indutivo continúan a ser moito máis frecuentes na literatura, debido en grande medida á inexistencia dunha teoría global, ampla e probada, que poida ser utilizada con garantías en calquera traballo de estudio de cambios de uso (Ramankutty, 2006). O grande interese das aproximacións de natureza indutiva radica na súa capacidade para explorar a localización xeográfica dos procesos, as forzas que actúan sobre eles, e a rapidez con que se desenvolven.

\section{Obxectivos}

O traballo que se presenta ten como obxectivo a caracterización, desde o punto de vista das características de produtividade da terra (biofísicas) e das parcelas (estruturais), das áreas suxeitas a uso agrícola nos anos 1956 e 2004 así como daquelas que experimentaron transicións de uso desde ou cara o uso agrícola entre eses mesmos anos. A área seleccionada para a realización do estudio, a comarca luguesa da Terra Chá (figura 1), é a comarca máis extensa de Galicia $\left(1.822 \mathrm{~km}^{2}\right)$ e destaca por ser un dos expoñentes da especialización gandeira dentro do conxunto de Galicia (Iglesias Patiño et al., 2000).

En resumo, o traballo proponse como obxectivo estudar as posibles correlacións entre un conxunto de variables explicativas e cinco variables de cuberta do solo e cambios de cuberta: (1) a distribución da Superficie Agrícola Utilizada (SAU) en 1956 e (2) en 2004; (3) a repoboación de terras de cultivo ou prados (SAU-arborado); (4) o abandono da terra (SAU-mato); e (5) a roturación de áreas de mato (mato$\mathrm{SAU}$ ). Os modelos construídos para as correlacións mencionadas teñen unha dobre finalidade: inferir información acerca das localizacións máis frecuentes e, nun segundo plano, elaborar hipóteses acerca das súas posibles causas.

\section{Material}

A información de partida empregada no estudio é unha mostra sistemática de 7.274 puntos (seguindo unha malla cadrada de $500 \mathrm{~m}$ de lado), na que se dispón de información relativa ó tipo de cuberta (agrícola, mato, arborado, outras) tanto para o ano 1956 como para 2004. A cuberta correspondente a 1956 foi obtida mediante fotointepretación das fotografías aéreas do voo da serie $B$ do Centro Cartográfico e Fotográfico do Exército do Aire (1956-1957), mentres que a cuberta de 2004 foi derivada de xeito automático do Sistema de Información Geográfica de Parcelas Agrícolas (SIGPAC) na súa primeira edición (o proceso aparece detallado en Corbelle Rico \& Crecente Maseda, 2008). A mostra descrita complementouse cun conxunto de variables de tipo biofísico, estrutural e socioeconómico (táboa 3) procedentes de diversas fontes cartográficas e documentais. As variables biofísicas foron obtidas da base cartográfica de Galicia a escala 1:5.000, o Atlas climático de Galicia (Martínez Cortizas, A. \& Pérez Alberti, A., 1999), as bases de datos do antigo Instituto Nacional de Meteoroloxía (2000), a base cartográfica do Sistema de Información Territorial de Galicia (2009), e o Sistema de Información Geográfica de Parcelas Agrícolas (Min. De Medio Ambiente, Medio Rural y Marino, 2009). As variables estruturais foron obtidas do xa citado SIGPAC, das bases de datos da elaboración da Enquisa de Infraestruturas e Equipamentos Locais da provincia de Lugo

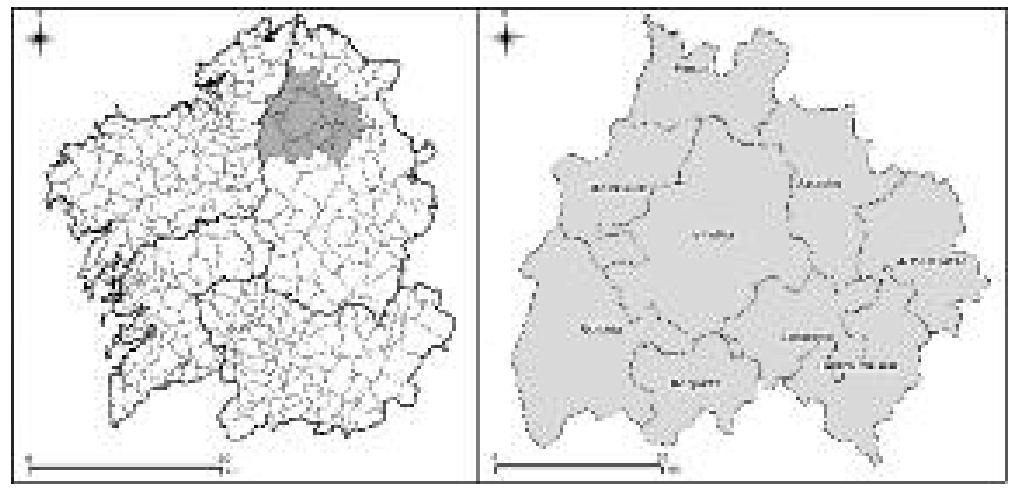

Figura 1.- Situación da comarca de Terra Chá en Galicia 
(Laboratorio do Territorio, 2009) e do traballo de Miranda Barrós (2001). As variables de carácter socioeconómico deriváronse dos Censos Agrarios de 1962 e 1999 (INE, 1964, 2009a) e do Padrón Municipal de Habitantes (INE, 2009b). O tratamento estatístico de todo o traballo foi realizado co programa estatístico $R$ ( $R$ Development Core Team, 2008) complementado co paquete adicional "spdep" (Bivand et al., 2008). A preparación de variables realizouse coa axuda dos sistemas de información xeográfica ArcGIS e GRASS GIS

\section{Metodoloxía}

\section{Selección de variables}

Os casos de utilización de regresión para investigar as forzas impulsoras de cambios de uso do solo son diversos, e esta diversidade tamén se manifesta nas variables explicativas consideradas. En xeral, aínda que non sempre apareza reflectido de modo explícito, os investigadores tenden a escoller as variables en función do seu efecto previsible sobre os cambios que se estudan. Un caso no que esta distinción se menciona explicitamente é o de Gellrich et al. (2006), que para estudar o abandono da actividade agrícola na montaña suíza divide as variables en (1) relacionadas cos beneficios económicos (p. ex. radiación solar, profundidade do solo) e (2) relacionadas cos custos (p. ex. pedregosidade, pendente). Por outra parte tamén é certo que na maioría dos casos os autores tenden a incluír unha mistura de variables de natureza biofísica, socioeconómica ou estrutural na elección das cales a dispoñibilidade parece xogar un papel fundamental. Unha revisión das variables máis empregadas na bibliografía (táboas 1 e 2) mostrounos que as variables biofísicas máis comúns son a altitude e pendente, seguidas da radiación solar teórica e a orientación do terreo. Variables máis difíciles de obter, como por exemplo as relacionadas coas características edáficas, aparecen nun número moito menor de traballos. Entre as variables estruturais, as máis comúns son a distancia a vías de comunicación e a distancia a núcleos de poboación, mentres que variables máis difíciles de obter como a distancia da parcela ata a vivenda do propietario só aparecen nun traballo concreto no que a superficie de estudio é relativamente reducida e a estrutura de poboación simple (Overmars et al., 2007). Entre as variables socioeconómicas, finalmente, destacan pola súa frecuencia de aparición a evolución da poboación total e a evolución da poboación activa mentres que outras (de novo máis difíciles de obter) como o prezo da terra, ou a evolución da cabana gandeira, por exemplo, só aparecen de modo puntual.

O criterio utilizado para recompilar variables neste traballo (táboa 3) foi o de incluír, ata onde fose posible, o maior número de variables utilizadas na bibliografía, co único límite derivado da dificultade de obtención. Por exemplo, dentro do grupo de variables biofísicas non se inclúen variables edáficas, xa que non existe para a zona de traballo unha fonte de información coa escala axeitada: o mapa de solos de Galicia, actualmente en execución, aínda non cobre a provincia de Lugo (Sistema de Información Ambiental de Galicia, 2009). Noutros casos optamos por incluír algunha variable non mencionada na bibliografía sobre cambios de uso do solo, pero da que outros traballos teñen demostrado a relación coa evolución do uso agrícola, como é o caso da concentración parcelaria (Crecente Maseda et al., 2002; Miranda Barrós et al., 2006). A inclusión desta última variable choca coa inexistencia dunha fonte cartográfica que inclúa os límites das áreas de concentración, razón pola que se optou por tomar a variable a nivel parroquial (porcentaxe da superficie parroquial afectada por concentración) do traballo de Miranda Barrós (2001). Outra variable incorporada é a referente ás áreas afectadas polos traballos do Instituto Nacional de Colonización durante os anos 50 e 60: a pertenza ou non a unha das áreas de colonización foi incluída como variable xa que existen motivos para pensar que tamén nestes casos a permanencia da actividade agrícola debeu ser superior. Finalmente, incluímos unha variable adicional relacionada co tipo de propiedade a través da pertenza ou non a un monte veciñal en man común (MVMC), así como algunhas variables relativas á parcela individual: a superficie total e o seu índice de forma (relación entre área e perímetro), ou a adxacencia a vías de comunicación.

A incorporación de variables socioeconómicas introduce algún problema metodolóxico adicional: se ben é certo que algunhas das variables incluídas nos dous grupos anteriores (biofísicas e estruturais) non están libres de variacións asociadas ó paso do tempo, certamente pódese asumir nelas certa estabilidade. Incluso no caso das variables estruturais, onde a variación pode ser máis forte, a inclusión da concentración parcelaria como variable (unha das accións que máis modifican a estrutura) permite integrar estas variacións con certa facilidade. Esta pequena disgresión metodolóxica faise máis aceptable se consideramos que os factores biofísicos e estruturais non son estritamente causas dos cambios que intentamos estudar senón "facilitadores", e que polo tanto as variacións que puideran ter lugar ó longo do período estudado probablemente actuaron en diferentes sentidos e non terían por que inducir sesgo nos resultados. Sen embargo no caso dos factores socioeconómicos a relación causa-efecto é máis obvia, complicada pola existencia dun desfase temporal de magnitude descoñecida entre os cambios socioeconómicos e a súa manifestación na variación da cobertura do terreo. Por esta razón Gellrich et al. (2006) manteñen, con criterio que nos parece acertado, que as variables socioeconómicas a incluír no modelo deben de corresponder ó período temporal inmediatamente anterior ó estudado. Pero manter este criterio neste caso faise difícil por canto o período estudado ten como data de inicio o ano 1956 e os datos estatísticos da época son cando menos escasos, e en xeral non están dispoñibles coa desagregación espacial que sería necesaria. Unha solución de compromiso consiste en utilizar a variación temporal das variables durante o período estudado: aínda que esta aproximación fai imposible suxerir relacións de causalidade, si permitiría cando menos establecer relacións entre a dinámica das cubertas do solo e as variables socioeconómicas. 


\begin{tabular}{|c|c|}
\hline Varlables & Autor(es) $)^{+}$ \\
\hline 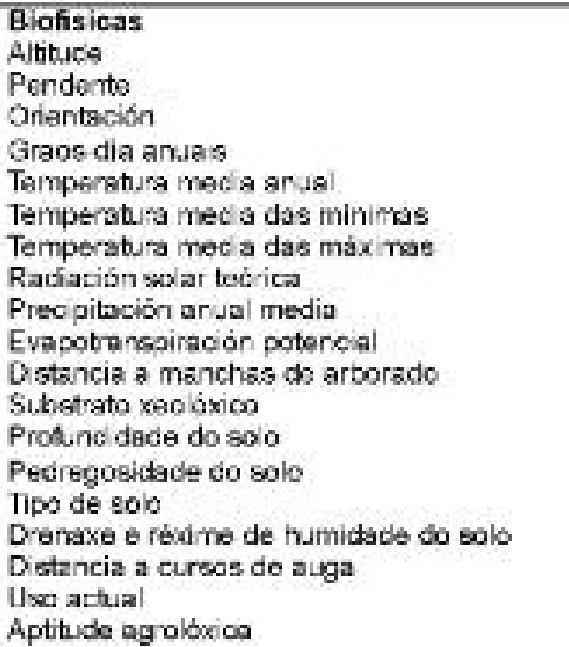 & $\begin{array}{l}1,2,4,5,8,9,11 \\
2,3,4,5,7,8,9,10,11 \\
6,9,10 \\
3 \\
6,11 \\
11 \\
11 \\
3,8,9,10 \\
3,11 \\
3 \\
2,3 \\
2,11 \\
3,10 \\
3 \\
10 \\
9 \\
8,7 \\
2,6 \\
6\end{array}$ \\
\hline 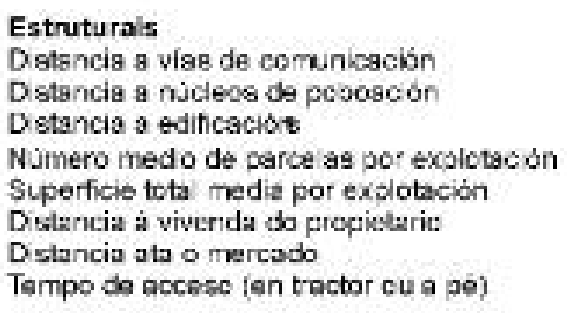 & $\begin{array}{l}5,6,10 \\
2,3,5,6 \\
3 \\
2,3,11 \\
3,11 \\
7 \\
7 \\
4\end{array}$ \\
\hline 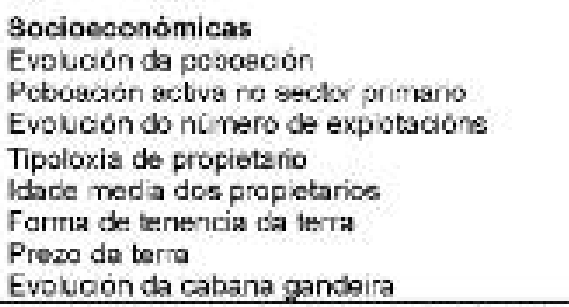 & $\begin{array}{l}3,5,6 \\
2,3,6,11 \\
3 \\
10 \\
8,11 \\
4 \\
11 \\
11 \\
\end{array}$ \\
\hline
\end{tabular}

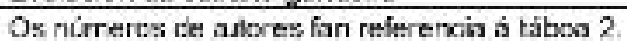

Táboa 1.- Variables atopadas en estudios sobre abandono da actividade agrícola

\begin{tabular}{|c|c|c|}
\hline & Autor(es) & Proceso estudiado \\
\hline 1 & Tailefumier \& Piegay (2003) & Abandano da actividade agricola \\
\hline 2 & Kobler et al. (2005) & Abandono da actrvade agricola \\
\hline 3 & Gellich et al (2005) & Mbandone da actividade agrícola \\
\hline 4 & Mottet et al. $\{2006\}$ & Intensificación / exteneificación do cultivo \\
\hline 5 & Vagen $(2006)$ & Deforestación e intensif cación do cultivo \\
\hline 6 & Millington (2007) & Abandono da actividade agricola \\
\hline 7 & Overmars et al. (2007) & Evolución de ciferentes cu tivos \\
\hline 8 & Pueyo \& Begueria (2007) & Abandono da actividade agricola \\
\hline 9 & Tassen at al. $(2007)$ & Abandono da ackivifade agricola \\
\hline 10 & van Coom \& Bakker $\{20 \mathrm{C} 7\}$ & Abandono da actividade agricola \\
\hline 11 & Serra et sl. (200a) & Evolucion de ciferentes cult vos \\
\hline
\end{tabular}

Táboa 2.- Clave de autores para a táboa 1

\section{Regresión loxística}

A regresión loxística é unha forma particular de modelo lineal xeneralizado, baseada na transformación dunha variable lóxica (que toma os valores "verdadeiro" e "falso") nunha variable numérica con valores entre $-\infty$ e $+\infty$ (Menard, 2001). A regresión realízase entre a variable transformada mediante $\mathrm{o}$ Logit da probabilidade $p$ dun suceso (por exemplo un determinado cambio de cuberta) $\mathrm{e}$ as variables (cualitativas ou cuantitativas) que se desexe, segundo a expresión:

$$
\log \dot{x}(p)-\log \left(\frac{p}{1-p}\right)-\beta_{i}-\beta_{1} x_{2}-\varepsilon
$$

Ecuación 1 


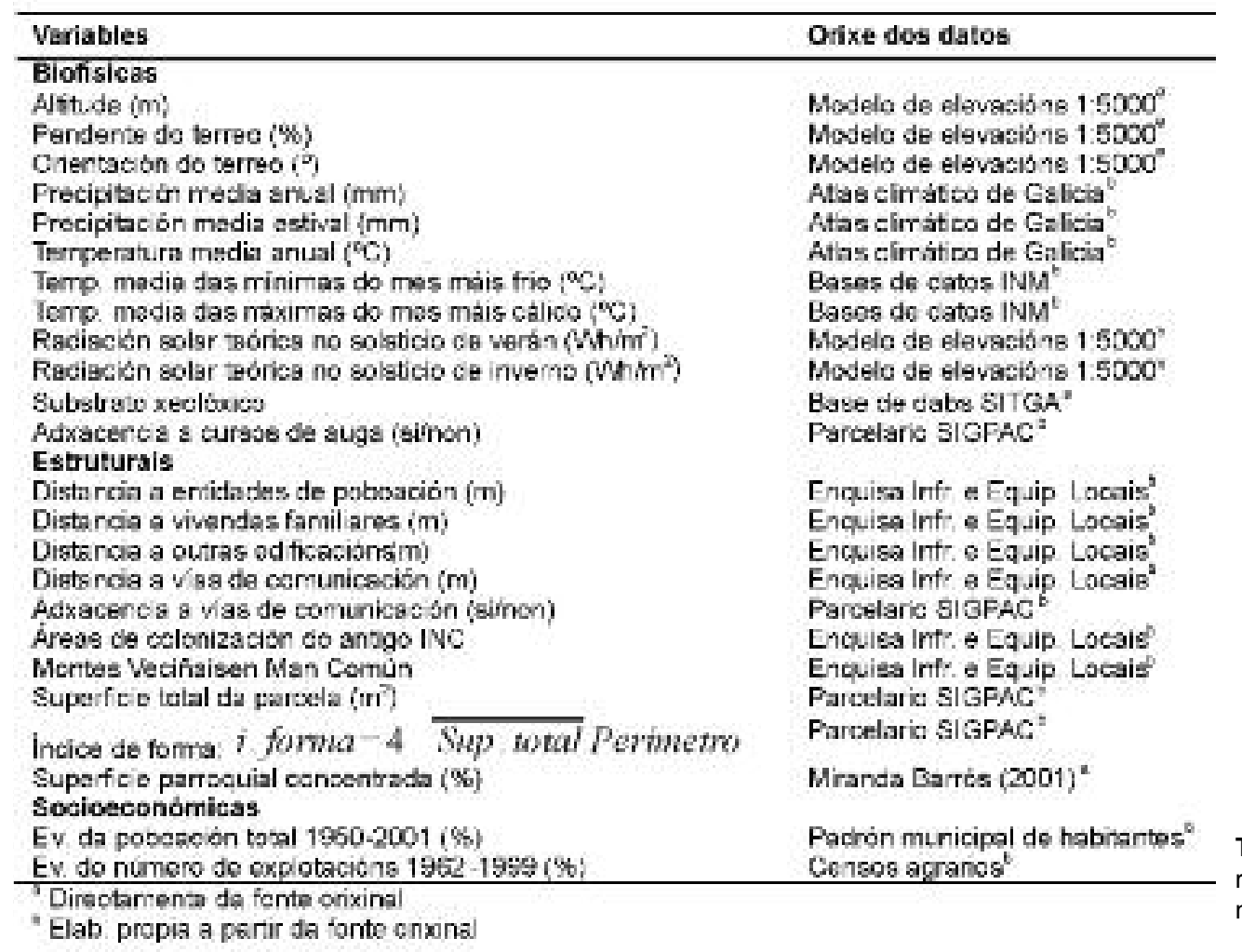

Táboa 3.- Variables recompiladas para o seu uso no traballo

\section{Análise de correlación entre variables}

As variables inicialmente seleccionadas foron sometidas a análise para evitar a introdución de multicolinearidade nos modelos de regresión, dado que a correlación entre variables explicativas (colinearidade) afecta negativamente á fiabilidade dos coeficientes que resultan do axuste. Algúns dos métodos propostos para detectar a presenza de colinearidade son o axuste de modelos de regresión lineal entre pares de variables (Menard, 2001) ou o uso dalgún coeficiente de correlacion como o de Pearson (Millington et al., 2007). Neste caso optamos por utilizar o coeficiente de correlación non paramétrico $\rho$ de Spearman, para avaliar por separado a correlación entre variables biofísicas e estruturais. A elección do coeficiente de Spearman derívase de que a distribución das variables orixinais non segue unha distribución normal (a aplicación do test de normalidade de Shapiro-Wilk obriga a rexeitar a hipótese de normalidade en tódolos casos). En principio, valores de $\rho$ maiores de 0,5 ou inferiores a $-0,5$ indican certo grao de correlación, se ben non existe consenso en canto a que valor do coeficiente pode ser considerado representativo dunha correlación "forte" e calquera elección ó respecto é claramente arbitraria. Aínda que algúns autores optan por eliminar variables con coeficientes de correlación superior a 0,5 (Millington et al., 2001), neste traballo optamos por tomar un valor relativamente conservador $(0,8)$ para evitar eliminar da análise demasiada información. En consecuencia, descartamos da análise as variables "Precipitación estival" (fortemente correlacionada con "Precipitación anual"), "Temperatura media anual" (relacionada con "Altitude"), "Temperatura media das máximas do mes máis quente" (relacionada coas variables "Temperatura media das mínimas do mes máis frío" e "Altitude"). Entre as variables estruturais, polo contrario, non atopamos correlacións que xustifiquen a exclusión de ningunha delas.

\section{Análise de autocorrelación}

Dise que unha variable distribuída espacialmente presenta autocorrelación cando puntos de mostraxe próximos entre si tenden a presentar valores similares. Se unha variable presenta un valor elevado de autocorrelación, a hipótese de independencia dos datos introducidos na regresión resulta comprometida e por extensión tamén os coeficientes resultantes da análise. Para medir o grao de autocorrelación das variables consideradas utilizamos o coeficiente I de Moran (Cliff \& Ord, 1981). O coeficiente I toma normalmente valores entre -1 e 1 e pode ser interpretado de maneira similar a outros coeficientes de correlación: valores próximos a 1 indican autocorrelación positiva (a variable tende a presentar valores similares en localizacións próximas entre si), valores próximos a -1 indican autocorrelación negativa (zonas próximas presentan diferencias maiores entre si que coas situadas a distancias medias) e valores próximos a 0 indican unha distribución espacial completamente aleatoria. Pese ó que se puidera supoñer, o valor esperado de I baixo a hipótese nula de non autocorrelación non é igual a cero senón que ven dado por:

$$
\begin{aligned}
& \Gamma_{0}--I i(n-1) \\
& \text { ande n a o ruzero ols abservacions, e neste caso lama a vabe } \\
& I_{0} \quad-1 ;(7274-1)-000137
\end{aligned}
$$

Ecuación 2 
A aplicación do coeficiente ó conxunto de variables seleccionadas deu en tódolos casos o resultado significativo de autocorrelación positiva. Esta situación vai en contra da condición de independencia entre os datos, co resultado de que o axuste do modelo mellora artificialmente e os coeficientes das variables explicativas identifícanse como significativos con excesiva facilidade (Cliff \& Ord, 1981). Co fin de evitar esta situación, empregamos un modelo con compoñente autorregresiva, definido de modo xenérico pola expresión (Cliff \& Ord, 1981):

$$
\operatorname{Jog} \dot{x}(p) \log \left(\frac{p}{1-p}\right)-\ddot{\mu}_{0}-\beta_{i} x_{;}-\beta_{*} w y-p^{2}
$$

Ecuación 3

onde a única diferencia co modelo loxístico definido na ecuación 1 é a inclusión dun termo adicional $\beta_{w}$ wy composto por un coeficiente de regresión $\beta_{w}$ e unha autocovariable $w y$. Esta última é o resultado de calcular, para cada punto de mostraxe, a suma dos valores da variable resposta y nos puntos veciños, ponderada polo inverso da distancia ó punto analizado.

\section{Axuste dos modelos}

A partir das variables seleccionadas realizouse o axuste de cinco modelos de regresión loxística. Co fin de que os coeficientes de regresión calculados para as diferentes variables foran estandarizados e polo tanto comparables entre si (Menard, 2001), as variables numéricas foron normalizadas antes da introdución nos modelos.

Dos cinco modelos totais, dous foron orientados a caracterizar a localización da SAU en cada un dos puntos no tempo (1956-1957 e 2003-2004), no primeiro dos cales excluímos as variables "variación da poboación" e "variación do número de explotacións" porque se refiren a un intervalo temporal posterior ó momento analizado. Os tres modelos seguintes céntranse en cambios de cuberta concretos, de SAU en 1956 a mato en 2003, de SAU a arborado e de mato a SAU. Do total de puntos dispoñibles para o axuste, excluímos os que correspondían a cubertas artificiais (vías, edificacións) en 1956 para a caracterización da SAU dese mesmo ano (en total o modelo axustouse sobre 7100 puntos). No modelo correspondente á SAU de 2003 utilizouse o mesmo criterio (6962 puntos en total). Nos tres últimos modelos o número de puntos corresponde ó total de puntos identificados como SAU en 1956 (3312 puntos) para as transicións SAU-mato e SAU-arborado, e os identificados como mato en 1956 (3250 puntos) no caso restante.

Para estimar a bondade de axuste dos modelos, e dada a natureza discreta das variables modelizadas, resulta interesante coñecer a frecuencia coa que o modelo predí correcta ou incorrectamente o valor real da variable dependente (Menard, 2001). Tendo en conta que o que o modelo produce son probabilidades e que estas deben ser comparadas con situacións reais de "presenza" ou "ausencia", é necesario utilizar un umbral que estableza cando o modelo predí "presenza" e cando "ausencia": o habitual é utilizar o umbral de $p=0,5$, pero calquera outro tamén podería ser utilizado coa conseguinte variación nos acertos correspondentes (figura 2). Para evitar a ambigüidade inherente á elección dun umbral, a bondade do modelo pode ser avaliada de modo máis fiable a través da área baixo a curva ROC (Receiver Operating Characteristic), unha representación da proporción de "presenzas" acertadas fronte á proporción de "presenzas" preditas de modo erróneo para diferentes valores do umbral. A área baixo a curva ROC (figura 3) toma valores

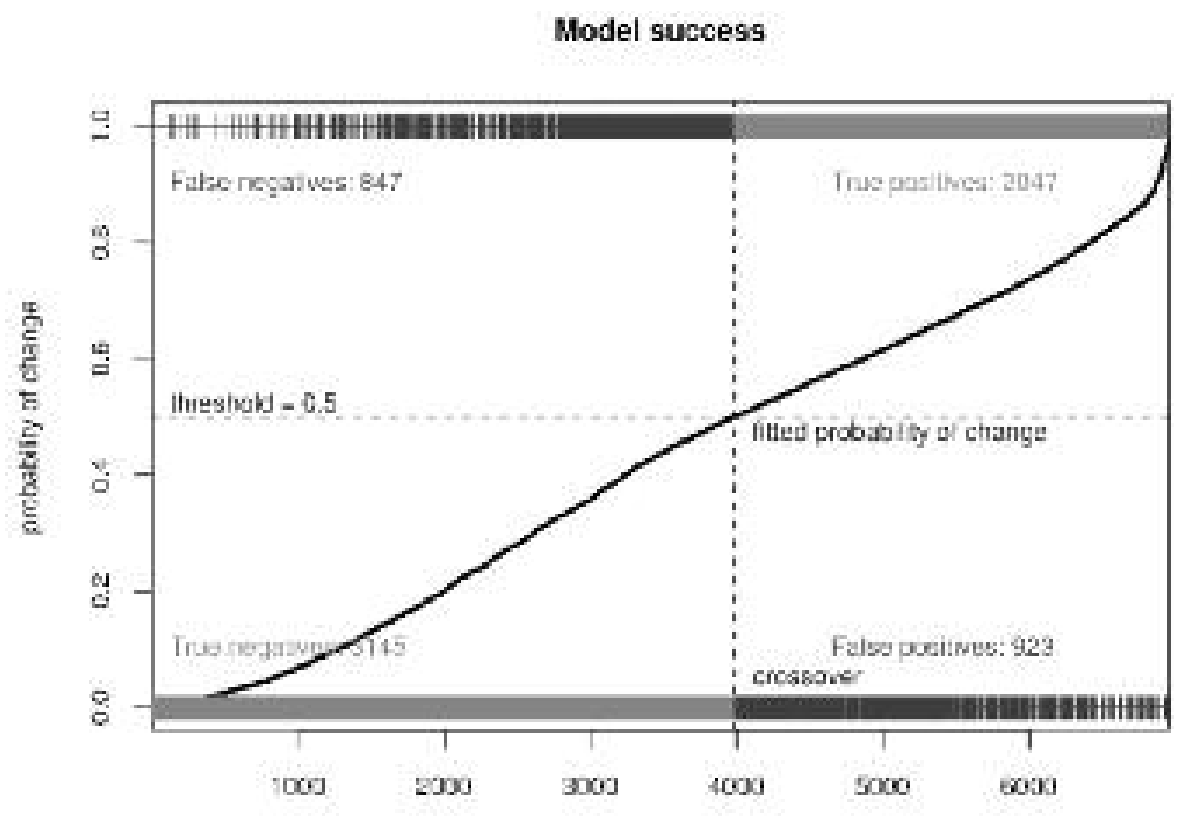

Senatrity: 0.7073 ; Spocilcity: 2.7731
Figura 2.- Modelo de regresión loxística aplicado á presenza de SAU en 2003 
entre 0 e 1 e compárase coa área baixo a diagonal, que representa a probabilidade de acertos dun modelo ó azar e ten un valor de 0,5 . Aínda que non existe un criterio único para a avaliación da bondade deste parámetro unha referencia válida é a de Lesschen et al. (2005), que considera aceptable para un estudio deste tipo o valor de 0,7 .

\section{Resultados e discusión}

Os resultados do axuste dos diferentes modelos aparecen resumidos na táboa 4: esta mostra os coeficientes calculados para as variables que foron identificadas como significativas a un nivel de 0,05 e inclúe tamén entre parénteses os coeficientes que presentaron un nivel de significación entre 0,10 e 0,05. En xeral pódese dicir que o axuste dos modelos é bo: o valor da área baixo a curva ROC oscila entre valores aceptables e bos para este tipo de estudios (de 0,70 a 0,82) similares ós obtidos por outros autores (Gellrich et al., 2006; Braimoh et al., 2007; Serra et al., 2008). Outro aspecto a resaltar dos cinco modelos é o valor positivo do coeficiente correspondente ás autocovariables, o que confirma a validez do modelo autorregresivo para filtrar a autocorrelación nas variables de entrada. Tamén interesa resaltar que só dúas variables aparecen como significativas (para un nivel de 0,05) nos cinco modelos: a pendente do terreo, e a distancia a outras edificacións.

Ollando para os coeficientes pódense apreciar varias similitudes entre os modelos axustados para a SAU de 1956 e 2003. En ambos casos a variable máis influínte no resultado é a pertenza a zonas de colonización do INC, se ben en sentido oposto en cada ano: a presenza de SAU nas actuais áreas de colonización era menos probable que no resto do territorio en 1956 pero máis en 2003, o que era de esperar dado que se trataba de áreas de monte veciñal con aproveitamento principal de toxo e que non foron ocupadas polos primeiros colonos ata 1959 (Cardesín Díaz, 1987). A segunda variable por orde de influencia é a pendente, que en ambos casos actúa en sentido negativo, tamén de acordo co esperable (menor probabilidade de presenza de SAU conforme a pendente se incrementa). A distancia a entidades de poboación e a pertenza a MVMC sitúanse a continuación, ambas con influencia negativa. A superficie da parcela relaciónase cunha menor presenza de uso agrícola, o que está en relación co feito de que as parcelas de maior tamaño corresponden a montes veciñais e estaban con frecuencia cubertas de mato. Das variables socioeconómicas utilizadas para caracterizar a SAU de 2003 a variación de poboación non aparece como significativa pero si a variación no número de explotacións. En resumo, un intento de interpretación dos coeficientes calculados daría a seguinte visión da SAU de 1956: presente fundamentalmente en áreas de baixa pendente, parcelas de pequeno tamaño pero forma compacta e facilmente accesibles (preto de entidades de poboación, das edificacións das explotacións e das estradas) e fóra das áreas comunais (que serían utilizadas preferentemente para mato e só ocasionalmente para o cultivo de cereal). Unha situación similar ocorrería coa SAU de 2003 coa salvidade de que aquelas áreas de monte comunal ocupadas polas áreas de colonización son agora preferentemente utilizadas como SAU.

Os modelos de cambio entre 1956 e 2003, pola súa parte, mostran diferentes variables significativas en cada caso. A transición de SAU a mato, aparece favorecida pola maior altitude, pendente, distancia a entidades de poboación e distancia a outras edificacións, mentres que a adxacencia a cursos de auga ou a maior superficie das parcelas actuarían

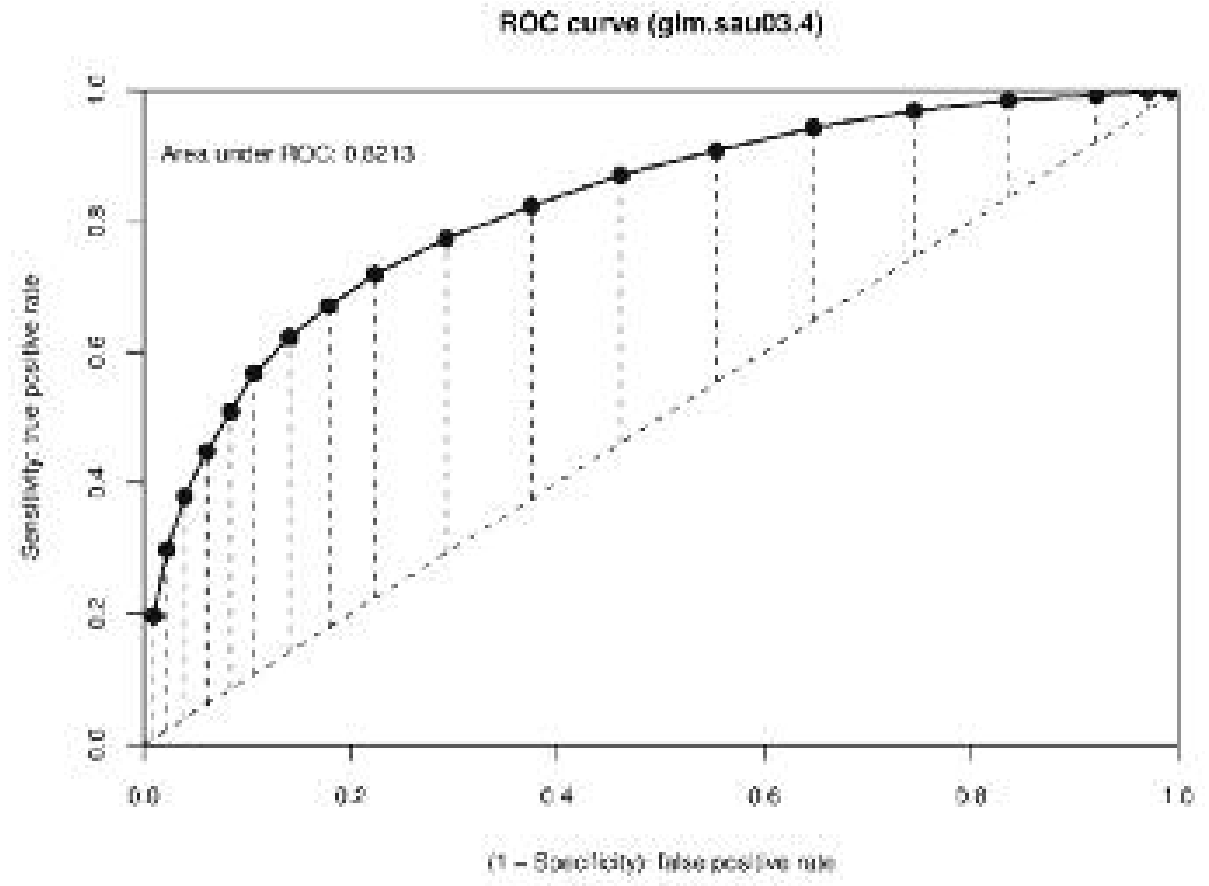

Figura 3.- Curva ROC para o modelo aplicado á presenza de SAU en 2003 
en sentido contrario. Destes resultados parece razoable inferir que as parcelas de máis difícil mecanización (reflectida por unha maior pendente) e máis afastadas (maior altitude, distancia desde os poboamentos e distancia desde as explotacións) foron relegadas a un uso moi extensivo ou simplemente abandonadas. $O$ feito de que a variable "superficie" actúe aquí no sentido esperado en comparación co modelo da SAU de 1956 (parcelas de maior superficie manteñen con maior probabilidade a actividade agrícola) explícase porque -ó contrario que neste último- no modelo da transición a mato a mostra está limitada ós puntos que eran SAU en 1956.

\begin{tabular}{|c|c|c|c|c|c|}
\hline Varlables: & & & Medelo & & \\
\hline & SAU 1956 & SAU 2003 & Salu-Mato & SAL-ARbCrado & Mato-SAU \\
\hline (intercesti) & $-0,20$ & $-0,71$ & -1.61 & $-1,2$ & $-1,71$ \\
\hline Altitude & & 0,21 & 0,33 & $-0,45$ & $(0,1$ ة) \\
\hline Pencient: & $-0,62$ & $-0,96$ & 0,34 & 097 & $-1,01$ \\
\hline Orentación & & (010) & & & (0.19) \\
\hline T minirras & & $(0,10)$ & & & $(0,10)$ \\
\hline fad solar varḱn & -0.30 & & & 0,57 & $(-0,32)$ \\
\hline Fiad soler inverno & 0,17 & 0,25 & & $-0,3$ & 0.31 \\
\hline Xeoloxia & & & & & \\
\hline Adx auga & & 0,26 & -0.45 & & 0,34 \\
\hline Suserficis & $-0,23$ & 0.13 & $-0,34$ & $\langle-0,28\rangle$ & \\
\hline Ind forma & 0,12 & 0,11 & & $(C, 09)$ & 0.23 \\
\hline $\begin{array}{l}\text { D enidatex } \\
\text { D vivendas }\end{array}$ & $-0,52$ & $-\mathrm{C}, 39$ & 0.41 & & \\
\hline D putras edif & -0.32 & $-\mathcal{C .} 69$ & 0.38 & 0,62 & -0.39 \\
\hline D costracas & 0.19 & (c.13) & & & 0,21 \\
\hline Adtx visa & $(-0,12)$ & & & & 0.45 \\
\hline Colonizgdón & $-0,95$ & 1,55 & & & 1,25 \\
\hline MVMC & $-0,46$ & $-0,59$ & & & $-0,48$ \\
\hline Prop conc parcelaria & - & 0,12 & & $-0,18$ & 0,12 \\
\hline Varpos & - & & & & \\
\hline Var expiat & - & 010 & $\{0,12\}$ & & 026 \\
\hline Autorovariat:le & 0.53 & 0.56 & 0.28 & 0.41 & 0.58 \\
\hline Area baixo ROC & $0,790^{\circ}$ & 0,8224 & 0,7208 & 0,7183 & c, 2238 \\
\hline
\end{tabular}

Táboa 4.- Resultados dos modelos de regresión loxística (coeficientes significativos)

O segundo cambio modelizado é a repoboación de terras agrícolas (SAU-arborado). A repoboación aparece asociada ás zonas de maior pendente e distancia ata as explotacións pero, en contraste con aquel, a influencia das variables altitude é agora oposta e suxire que a repoboación se concentrou en áreas relativamente baixas. Tamén destaca que a distancia a entidades de poboación non é agora significativa, pero si a proporción de superficie parroquial concentrada. De acordo cos resultados a repoboación de terras agrícolas tivo lugar preferentemente en áreas difíciles de mecanizar e afastadas das explotacións, pero non necesariamente afastadas das entidades de poboación nin de moita altitude. As razóns que explicarían este comportamento (tamén observado nos traballos de Marey Pérez et al., 2006 ou Calvo Iglesias et al., 2006) non son fáciles de propoñer, pero poderían ter relación cun relativo esquecemento das áreas máis remotas, cos custos asociados á plantación en áreas de difícil acceso, ou cunha visión das plantacións forestais excesivamente produtivista e a curto prazo que concentrou a repoboación nas terras máis accesibles e máis aptas para as especies de crecemento rápido.

O último cambio modelizado é a roturación de terras para uso agrícola (mato-SAU). Como sería esperable a resposta das variables significativas é en grande medida oposta ás detectadas nos outros dous cambios modelizados. En primeiro lugar, a pendente actúa neste caso en sentido negativo, indicando que a roturación tivo lugar fundamentalmente en áreas de máis fácil mecanización. A accesibilidade (distancia a estradas, adxacencia a vías), a proximidade ás explotacións (distancia a outras edificacións), a produtividade (insolación de inverno sol355- e adxacencia a cursos de auga), e a forma da parcela, tamén aparecen como factores significativos. A maiores, as áreas roturadas aparecen asociadas preferentemente ás zonas de colonización e ás parroquias con maior porcentaxe de superficie concentrada, mentres que evitan a propiedade veciñal. Das variables socioeconómicas aparece como significativa a variación do número de explotacións, de xeito que a roturación aparece vinculada preferentemente ós concellos que perderon menos explotacións no período.

\section{Conclusións}

O traballo mostra a aplicación de técnicas de correlación estatística para obter información sobre a natureza e forzas impulsoras dos cambios da cuberta do solo. A natureza fundamentalmente exploratoria do traballo reflíctese tanto 
na propia elección do método, de natureza indutiva, como na elección das variables sometidas a análise, seguindo as empregadas noutros traballos similares e cun criterio relativamente oportunista (bastante común, por outra parte) de facilidade de obtención. Non obstante, os resultados mostran modelos con bondades de axuste que están en consonancia co observado na bibliografía, e as variables identificadas como significativas en cada caso, así como o sentido da súa influencia, están en xeral de acordo coa experiencia e cos ditados do sentido común.

En primeiro lugar, o traballo confirma o papel fundamental de dúas variables biofísicas, pendente e altitude, nas transformacións da cuberta do solo durante o período estudado, seguidas da radiación solar teórica. Outras variables biofísicas comunmente utilizadas tanto en estudios dos cambios de uso do solo como na elaboración de modelos de aptitude da terra como a orientación do terreo ou as variables climáticas de precipitación e temperatura non parecen xogar un papel relevante á escala da área de traballo. En segundo lugar, destaca a utilidade da variable "distancia a outras edificacións" (é dicir, edificacións non destinadas a vivenda) como un bo indicador da distancia ás explotacións existentes na zona e como unha variable de relevancia á hora de explicar os cambios ocorridos, así como a adecuada detección dos efectos da concentración parcelaria. En último lugar, a pesar dos problemas de escala presentes nas variables socioeconómicas (derivados da súa agregación espacial a nivel municipal), o traballo confirma a importancia que ten a variación do número de explotacións (en concreto sobre a maior taxa de roturación e menor taxa de abandono nos concellos onde o número diminuíu menos) e a escasa relevancia da variación da poboación total (que pode deberse a factores moi diferentes e alleos ó sector agrario).

Os resultados suxiren que o cese da actividade agrícola tivo lugar preferentemente nas áreas máis difíciles de mecanizar (pola maior pendente) e máis afastadas das explotacións, e que este deu paso a dous usos diferentes en función do carácter máis ou menos remoto: nas áreas de maior altitude e máis afastadas dos núcleos de poboación as parcelas foron prioritariamente reducidas a un uso moi extensivo de gandería ou ningún uso en absoluto, o que permitiu a expansión do mato, mentres que nas áreas de menor altitude os propietarios optarían fundamentalmente pola repoboación forestal.

A transición de sentido oposto, a roturación de áreas a mato para o seu uso agrícola, tamén estaría gobernado en parte pola pendente e a distancia ás explotacións: roturaríanse preferentemente as parcelas de máis fácil mecanización e máis próximas á explotación. Non obstante, a diferencia do abandono total, destaca neste caso a importancia de variables relacionadas coa produtividade (adxacencia a cursos de auga, insolación, índice de forma) e a accesibilidade das parcelas (adxacencia a vías, distancia a estradas). É dicir que se o abandono a mato tería lugar fundamentalmente por criterios de mecanización e distancia, os propietarios non tomarian a decisión de roturar unha parcela (un importante esforzo económico nalgúns casos) simplemente por estes dous criterios senón tamén pola rendibilidade futura que proporcionaría, de modo que as parcelas roturadas serían convenientemente seleccionadas por criterios de forma e acceso.

Agradecementos Agradecemos á Dirección Xeral de Investigación, Desenvolvemento e Innovación da Xunta de Galicia o financiamento aportado para a realización deste traballo a través do programa de contratos predoutorais "María Barbeito". Tamén nos gustaría agradecer a calidade do traballo realizado polos dous revisores anónimos do artigo.

\section{Bibliografía}

Anselin, L. (2002). Under the hood. issues in the specification and interpretation of spatial regression models. Agricultural Economics, 27: 247-267.

Bivand, R., with contributions by Luc Anselin, Assunçaõ, R., Berke, O., Bernat, A., Carvalho, M., Chun, Y., Dormann, C., Dray, S., Halbersma, R., Krainski, E., Lewin-Koh, N., Li, H., Ma, J., Millo, G., Mueller, W., Ono, H., Peres-Neto, P., Reder, M., Tiefelsdorf, M., \& Yu., D. (2008). spdep: Spatial dependence: weighting schemes, statistics and models. $\mathrm{R}$ package version 0.4-29.

Braimoh, A. K. \& Onishi, T. (2007). Geostatistical techniques for incorporating spatial correlation into land use change models. International Journal of Applied Earth Observation and Geoinformation, 9 (4): 438-446.

Calvo Iglesias, M. S., Fra Paleo, U., Crecente Maseda, R. \& Díaz Varela, R. (2006). Directions of change in land cover and landscape patterns from 1957 to 2000 in agricultura landscapes in NW Spain. Environmental Management, 38:921-933

Cardesín Díaz, J. M. (1987). Política agraria y transformaciones en la agricultura gallega: la zona de colonización de Terra Chá (1954-1973). Agricultura y Sociedad, 44: 243-280.

Cliff, A. D. \& Ord, J. K. (1981). Spatial processes: models and applications. Pion Limited, London.

Corbelle Rico, E. \& Crecente Maseda, R. (2008). Estudio da evolución da superficie agrícola na comarca da Terra Chá a partir de fotografía aérea histórica e mapas de usos, 19562004. Recursos Rurais, 1 (4):57-65.

Corbelle Rico, E. \& Crecente Maseda, R. (2009). Evolución histórica de la Superficie Agrícola Utilizada en Galicia (19622006). Integración de fuentes estadísticas y cartográficas (nota técnica). Economía Agraria y Recursos Naturales, 9 (2): 181-192.

Crecente Maseda, R., Álvarez López, C. \& Fra Paleo, U. (2002). Economic, social and environmental impact of land consolidation in galicia. Land Use Policy, 19: 135-147.

Everitt, B. S. \& Hothorn, T. (2006). A handbook of statistical analyses using R. Chapman \& Hall, Boca Ratón. 
Gellrich, M., Baur, P., Koch, B. \& Zimmermann, N. E. (2006). Agricultural land abandonment and natural forest re-growth in the Swiss mountains: A spatially explicit economic analysis. Agriculture, Ecosystems and Environment, 118: 93-108.

Iglesias Patiño, C. L., López Vizcaíno, M. E. \& Sánchez Fernández, P. (2000). Dimensionalidade da capacidade económica nas comarcas galegas. Revista Galega de Economía 9: 2, 67-90.

Instituto Nacional de Estadística (1964). Censo agrario de España (primero): octubre de 1962. (Tomos provinciales). INE, Madrid.

Instituto Nacional de Estadística (2009a). Censo Agrario de 1999. URL: http://www.ine.es/

Instituto Nacional de Estadística (2009b). Padrón Municipal de Habitantes. URL: http://www.ine.es/

Instituto Nacional de Meteorología (2000). Datos resumen de la red de estaciones termopluviométricas y completas del Centro Meteorológico Territorial de Galicia.

Kobler, A., Cunder, T. \& Pirnat, J. (2005). Modelling spontaneous afforestation in Postojna area, Slovenia. Journal for Nature Conservation, 13: 127-135.

Laboratorio do Territorio (2009). Enquisa de Infraestruturas e Equipamentos Locais 2005, Provincia de Lugo. Realizada en colaboración coa Deputación Provincial de Lugo. URL: http://idealugo.es/

Lesschen, J. P., Verburg, P. H. \& Staal, S. J. (2005). Statistical methods for analysing the spatial dimension of changes in land use and farming systems. LUCC Report Series, No. 7. The International Livestock Research Institute, Nairoby \& LUCC Focus 3 Office, Wageningen University.

López Iglesias, E. (2000). O sector agrario galego ás portas do século $\mathrm{XXI}$ : balance das súas transformacións recentes. Revista Galega de Economía, 9, 1: 167-196.

Martínez Cortizas, A. \& Pérez Alberti, A. (1999). Atlas climático de Galicia. Xunta de Galicia., Santiago.

Marey Pérez, M. F, Rodríguez Vicente, V. \& Crecente Maseda, R. (2006). Using GIS to measure changes in the temporal and spatial dynamics of forestland: experiences from northwest Spain. Forestry, 79: 409-423.

Menard, S. (2001). Applied Logistic Regression Analysis. Sage University Papers Series on Quantitative Applications in the Social Sciences, 07-106. Thousand Oaks, CA: Sage.

Millington, J. D. A. (2007). Modelling Land-Use/Cover Change and wildfire regimes in a Mediterranean Landscape. Tese Doutoral, King's College, Londres.

Millington, J. D. A., Perry, G. L. W. \& Romero Calcerrada, R. (2007). Regression techniques for examining land use/cover change: A case study of a Mediterranean landscape. Ecosystems, 10(4): 562-578.
Ministerio de Medio Ambiente, Medio Rural y Marino (2009). Sistema de Información Geográfica de Parcelas Agrícolas. URL: http://sigpac.mapa.es/fega/visor/

Miranda Barrós, D. (2001). Caracterización e avaliación da concentración parcelaria en Galicia. Proposta dun procedemento integral de ordenación rural baseado en métodos avanzados de SIX, fotogrametría dixital e análise multivariante. Tese Doutoral. Universidade de Santiago de Compostela.

Miranda Barrós, D., Crecente Maseda, R. \& Álvarez Taboada, M. F. (2006). Land consolidation in inland rural Galicia, NW Spain, since 1950: an example of the formulation and use of questions, criteria and indicators for evaluation of rural development policies. Land Use Policy, 23: $511-520$.

Mottet, A., Ladet, S., Coqué, N. \& Gibon, A. (2006). Agricultural landuse change and its drivers in mountain landscapes: A case study in the Pyrenees. Agriculture, Ecosystems and Environment, 114: 296-310.

Overmars, K. P., Verburg, P. H. \& Veldkamp, T. A. (2007). Comparison of a deductive and an inductive approach to specify land suitability in a spatially explicit land use model. Land Use Policy, 24: 584-599.

Pueyo, Y. \& Beguería, S. (2007). Modelling the rate of secondary succession after farmland abandonment in a Mediterranean mountain area. Landscape and Urban Planning, 83: 245-254.

R Development Core Team. (2008). R: A Language and Environment for Statistical Computing. R Foundation for Statistical Computing, Vienna, Austria. ISBN 3-900051-07-0. URL: http://www.R-project.org.

Ramankutty, N. (2006). Global land-cover change: recent progress, remaining challenges. En: E. F. Lambin \& H. J. Geist (Eds.). Land-Use and Land-Cover change. Local processes and global impacts. Springer-Verlag, Berlin, pp. 9-38.

Serra, P., Pons, X. \& Saurí, D. (2008). Land-cover and landuse change in a Mediterranean landscape: a spatial analysis of driving forces integrating biophysical and human factors. Applied Geography, 28: 189-209.

Sineiro García, F., López Iglesias, E., Lorenzana Fernández, R. \& Valdés Paços, B. (2004). La tipología de las explotaciones en función de su viabilidad económica y demográfica; aplicación a las explotaciones de bovino de Galicia. Economía Agraria y Recursos Naturales 4 (8): 63-85.

Sistema de Información Ambiental de Galicia (2009). Mapa de solos de Galicia a escala 1:50.000, Xunta de Galicia, Consellería de Medio Ambiente. URL: http://www.siamcma.org/siam/

Sistema de Información Territorial de Galicia (2009). Infraestrutura de Datos Espaciais de Galicia. Xunta de Galicia. URL: http://sitga.xunta.es/sitganet/ 
Soto Fernández, D. (2006). Historia dunha agricultura sustentábel. Transformacións produtivas na agricultura galega contemporánea, Xunta de Galicia, Consellería de Medio Rural.

Taillefumier, F. \& Piégay, H. (2003). Contemporary land use changes in prealpine Mediterranean mountains: a multivariate GIS-based approach applied to two municipalities in the Southern French Prealps. CATENA, 51: 267-296.

Tasser, E., Walde, J., Tappeiner, U., Teutsch, A. \& Noggler, W. (2007). Land use changes and natural reforestation in the Eastern Central Alps. Agriculture, Ecosystems and Environment, 118: 115-129. van Doorn, A. M. \& Bakker, M. M. (2007). The destination of arable land in a marginal agricultural landscape in South Portugal: an exploration of land use change determinants. Landscape Ecology, 22: 1073-1087.

Vagen, T. (2006). Remote sensing of complex land use change trajectories - a case study from the highlands of Madagascar. Agriculture, Ecosystems and Environment, 115: 219-228.

Walker, R. \& Solecki, W. (2004). Theorizing land-cover and land-use change: the case of the Florida everglades and its degradation. Annals of the Association of American Geographers, 94(2): 311-328. 